\title{
A Natural Capital Lens for a Sustainable Bioeconomy: Determining the Unrealised and Unrecognised Services from Nature
}

\author{
Andrew M. Neill ${ }^{1,2, * \mathbb{D}}$, Cathal $\mathrm{O}^{\prime}$ Donoghue ${ }^{2,3, *}$ and Jane C. Stout ${ }^{1,2, *(\mathbb{D})}$ \\ 1 Botany Department, School of Natural Sciences, Trinity College Dublin, Dublin 2, Ireland \\ 2 BiOrbic-Bioeconomy Research Centre, University College Dublin, Dublin, Ireland \\ 3 Policy Lab, National University of Ireland Galway, Galway, Ireland \\ * Correspondence: anneill@tcd.ie (A.M.N.); cathal.odonoghue@nuigalway.ie (C.O.); stoutj@tcd.ie (J.C.S.)
}

Received: 28 August 2020; Accepted: 21 September 2020; Published: 29 September 2020

\begin{abstract}
Human activity has led to degradation of the natural environment, with far-reaching impacts for society and the economy, sparking new conceptual framings for how people interact with, and depend upon, the environment. The bioeconomy and natural capital concepts both blend economics and natural sciences and propose new interdisciplinary, environmental sustainability framings. Despite this similarity, the two concepts are rarely applied together. This paper applies a natural capital lens to the bioeconomy at three different levels: environmental sustainability framings; experts' principles for a sustainable bioeconomy; and a case study of EU policy. We first construct an integrated cascade model that combines the unrealised potential of bioresources alongside unrecognised environmental services that tend to be systematically undervalued or ignored. Subsequently, we present five cornerstones identified from the sustainable bioeconomy-related literature from a natural capital perspective and highlight avenues of complementarity. The paper concludes with a policy case study of the EU Bioeconomy Strategy through a natural capital lens. There is evidence that the EU strategy has become increasingly aligned with the natural capital concept, but there is scope for further integration. The natural capital concept and related toolbox is an asset for the future bioeconomy to ensure it meets its environmentally sound and ecologically conscious objectives.
\end{abstract}

Keywords: bioeconomy; ecosystem services; environmental economics; environmental framings; environmental policy; EU policy; natural capital; sustainability; sustainable development

\section{Introduction}

\subsection{Environmental Sustainability Challenges and Concepts}

The last century of human development has brought remarkable improvements to health, wellbeing, and economic growth but has come coupled with environmental degradation that threatens to deplete natural systems beyond recovery [1,2]. Pressures on the environment are further exacerbated by an increasing population, growing resource demands, shifting lifestyle patterns, dependencies on non-renewables, and land-use change [3-5]. Growing recognition of environmental challenges, particularly climate change and biodiversity loss, has generated new ways to conceptualise how people interact with, and depend upon, the environment. Approaches to reconcile socio-economic aspirations with environmental limits-addressing negative "externalities" that threaten the health and wellbeing of both people and the planet-are gaining traction [6]. Two influential concepts at the forefront of policy and research that strive towards environmental sustainability are the bioeconomy and natural capital concepts. 
The bioeconomy concept has been popularised across policy and governance as a pathway to resolve unsustainable resource use and resulting environmental degradation [7]. It is premised on the replacement of fossil-based, non-renewable resources with biological alternatives. High-level representations of the bioeconomy concept in policy and academia associate it with economic growth, job creation, and value addition; move away from the linear, throughput economic model; and promote principles of renewable energy, circularity, and the cascading use of resources [8-10]. Environmental sustainability aspirations also drive the bioeconomy concept through the reduction of greenhouse gas emissions, the prevention of pollution that threatens ecosystems and biodiversity, and the efficient use of resources that limits exploitation and land-use change $[7,11]$. The bioeconomy represents a restructuring of the relationships between socio-economic systems and the environment, centred around bioresources and bioprocesses sourced from nature [12].

Despite striving for a "win-win" for both the economy and the environment [13], it should not be assumed that all interactions between the bioeconomy and the environment are positive [14,15]. Rather, the bioeconomy's contributions towards achieving environmental sustainability are recognised as conditional on the surrounding system and context-dependent $[9,14]$. Bioeconomic activities may have negative impacts upon the environment if implemented incorrectly [16-19]. Developing new ways to define, measure, and communicate the bioeconomy's environmental sustainability contributions are prerequisites to achieving the systemic change the bioeconomy aspires towards.

The natural capital concept uses the economic notions of "capital", "stocks", and "flows" to describe the environment, its functions, outputs, and benefits to humanity [20]. This economic lens connects socio-economic systems to the surrounding environment that they are embedded within, emphasising the services and resulting benefits provided-for free-from nature to people $[20,21]$. These ecosystem services, classified as provisioning, regulating, or cultural, are derived from the interactions between the living and non-living components of the environment; valuable to people and the economy because of the benefits they provide, from clean air and carbon storage to waste breakdown and food provision [22-24]. The concept has gained momentum through highly cited global assessments that estimate the value of nature's services as 2-3 times greater than global GDP-a strong argument that nature is vital to a healthy and functioning economy $[3,20,25,26]$. Natural capital has since branched into environmental sustainability practices such as its integration within national accounting standards [27], adoption within policy and decision-making spheres [28,29], and application as a tool to explore biodiversity's role in sustainable development and achieving the UN Sustainable Development Goals (SDGs) [30].

The natural capital and bioeconomy concepts both blend economics with natural sciences to illustrate the relationships and dependencies between human society and the environment. By re-establishing and reframing this fundamental linkage, via a systems approach to environmental management, policy, and decision-making, they seek to alleviate unsustainable environmental pressures that have resulted in the loss of nature across scales at an unprecedented rate [3]. Despite this similarity, the two concepts have different origins and spheres of influence: the natural capital concept emerged from environmental sciences and academia in the late 20th century and subsequently evolved into a decision-support tool $[20,28,31]$, whereas the modern bioeconomy concept emerged through high-level policy adoption and promotion through the early 21 st century (Figure 1) [7,8,32]. As a result, the two concepts are embedded within institutions, and leveraged by actors, in different ways, impacting their application and contributions towards environmental sustainability objectives. 


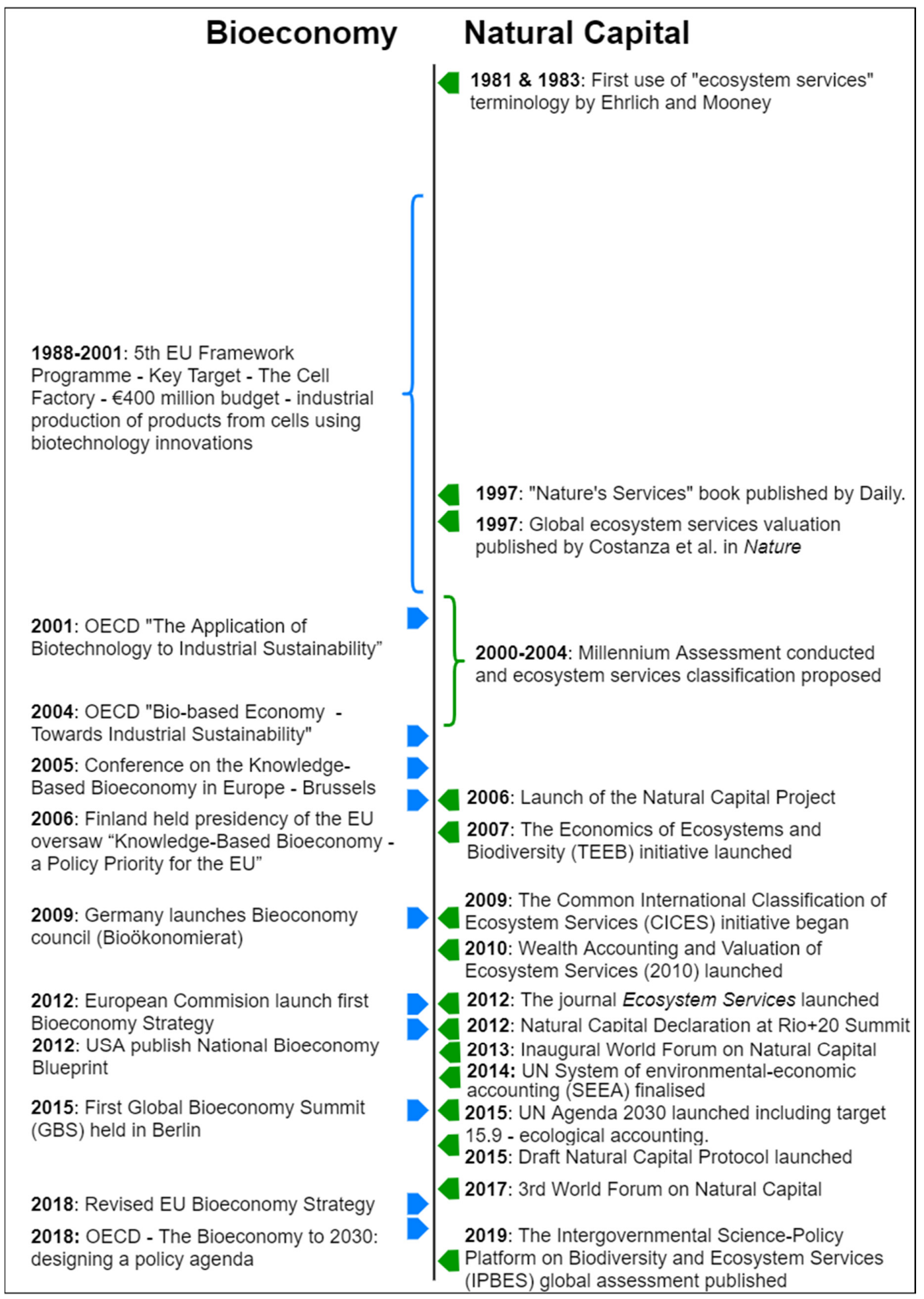

Figure 1. A timeline showing the emergence of the bioeconomy and natural capital concepts through key events since 1980 [22,32].

\subsection{The Knowledge Gap}

The sustainability of the bioeconomy cannot be assumed as an inherent characteristic but is instead conditional on the context and surrounding system $[14,33,34]$. Environmental sustainability research aims to inform these preconditions and steer the bioeconomy's development towards its sustainable 
ambitions and realisation of the SDGs $[9,11,35,36]$. The intersection of economics with natural sciences is common to both natural capital and the bioeconomy, yet they have seen little collaboration or interaction, remaining clustered within their respective areas of expertise. How the natural capital approach can contribute to shaping the environmental sustainability principles of the bioeconomy has not been explored in detail.

There are few instances in the academic literature that bring together both concepts. For example, the only reference that directly connects the two in its title, presents the importance of natural capital management to the success of a future wood-based bioeconomy and the forestry sector [37]. The language of "ecosystem services" is more commonly linked to the bioeconomy, but limited to a few examples such as the importance of soil ecosystem services for a future bioeconomy [38], the biosecurity dangers of an expanding bioeconomy [16], and the bioeconomy's emphasis on a subset of provisioning ecosystem services [39]. These examples use the language of natural capital, or adjacent themes, to illustrate arguments that environmental sustainability is a necessity for the bioeconomy's success, but do not connect the two on a conceptual level. Conversely, one paper does present a social-ecological systems framework for the bioeconomy that includes the variety of impacts and dependencies between the bioeconomy and the environment, but does not include any reference to natural capital or ecosystem services [12].

There is a knowledge gap related to linking the natural capital and bioeconomy concepts on a theoretical level that explores how these two similar concepts differ, and how natural capital can serve as a guiding principle for the realisation of a sustainable bioeconomy. We address this gap by applying a natural capital lens to the bioeconomy concept, creating a framework that recognises the value of ecosystems, biodiversity, and nature; informs integrated and coherent policy, research, and practice; and guides the realisation of an environmentally conscious, future bioeconomy. Creating this foundational linkage between the two concepts can serve as a "launching pad" for future studies and guide research questions towards practical, primary studies that advance knowledge of environmental sustainability.

\subsection{Objective and Structure}

In this paper, we bring together the bioeconomy and natural capital concepts to demonstrate how they can be related and the unrealised complementarities for policy, research, and practice. We first provide an overview of the natural capital and bioeconomy concepts, as represented in the literature, and explore their environmental framings. We then build on this overview and construct an integrated cascade model that combines the spectrum of different bioeconomy narratives within one shared framework. Secondly, we consider five cornerstones for a sustainable, future, global bioeconomy as presented in the literature [34] and use these cornerstones as a scaffold around which to compare the natural capital and bioeconomy concepts and identify areas of opportunity. We conclude with a case-study analysis of the EU Bioeconomy Strategy as seen through a natural capital lens, and end with a series of recommendations and opportunities for the future integration of the natural capital approach to the bioeconomy for coherent and synergistic policy design.

\section{Conceptual Framework and Environmental Framings}

\subsection{The Bioeconomy Concept}

The bioeconomy concept refers to the replacement of non-renewable resources with biological, renewable alternatives-spanning biopharmaceuticals, primary producing industries, bioenergy, biomaterials, biochemicals, and more-and accompanying changes to the economic system $[7,40]$. Nature provides these bioresources as products of ecosystem functioning, including biomass production, biological processes, and genetic resources [41]. Human civilisation has always depended upon biological resources and processes (such as agriculture and fermentation) and so it could be argued that the bioeconomy is not a new idea [6]. The modern conceptualisation of "bioeconomy" has 
evolved alongside advances in scientific knowledge and emphasises bioresources and novel uses, technological breakthroughs and their applications, and the replacement of non-renewables [8]. Therefore, the bioeconomy's success depends upon both primary production-the supply of bioresources-and advances in biotechnology and its applications-the efficient use of those resources that creates demand.

Today, the bioeconomy concept has successfully garnered political momentum and policy support such as the European Commission's bioeconomy strategy and the publication of over 45 national bioeconomy policy documents $[8,40,42]$. This momentum was generated by the perceived economic opportunities associated with novel bioresources and emergent biotechnological capabilities in high-income nations and further catalysed though supporting publications such as "Biotechnology for Sustainable Growth and Development" by the Organisation for Economic Co-operation and Development (OECD) in 2004 (Figure 1) [8,32,43]. The permeance of the bioeconomy is further enhanced by frequently cited economic statistics that estimate its value. For example, the EU's bioeconomy has a turnover estimated at $€ 2.3$ trillion and supports $8.2 \%$ of the EU workforce [44]. While a promising concept that has permeated policy across scales, questions remain over its scale, scope, and implementation.

There is no harmonised definition of the bioeconomy [10], and so its use spans a suite of competing narratives and visions for the future. These narratives range from a narrow focus on biotechnology, bioresources, and high-tech solutions-the "dominant" narrative-to a broad, systems approach of ecosystem functioning and public goods-the "rival" narrative [8,45]. As a result, the term encompasses many different meanings that are not applied consistently, creating a "master narrative" that lacks clarity $[10,45,46]$. This has been described as the "shades of green" of the bioeconomy as different applications have different environmental sustainability contributions and thus should not be assumed as equal [47]. Paradoxically, the blurred definition of the bioeconomy concept has allowed it to act as a bridge between a wide range of sectors and stakeholders [46,48]. As this study is limited to exploring the environmental pillar of sustainability, we focus on those narratives that are most relevant to the environment-rather than those of systemic economic change, political discourses, or specific synthetic biology case studies-either directly through the use of bioresources, or indirectly through developing new markets, value chains, and demand, while acknowledging that the concept has also been used in broader settings [49].

\subsection{The Natural Capital Concept}

The natural capital concept represents the environment as a series of "stocks" or "assets" that can be thought of as the building blocks of the environment-both the living and the non-living components [50]. The complex interactions between these building blocks produce ecosystem functions, giving rise to ecosystems. Some of those functions have a direct benefit to people, termed ecosystem services, and thus can be attributed value [21]. By recognising that all ecosystem services have value, but that not all are- or should be-monetised, the concept addresses the failure of traditional economics to capture only a subset of these services [22]. Natural capital accounting is an approach to measuring these stocks in terms of the quantity, quality, and attributes of those stocks; the service flows they give rise to; and the changes to those stocks over spatial and temporal scales [51].

The core language of natural capital and ecosystem services is attributed to academic publications in the early 1980s [22,31]. In 1997, the journal Nature published a breakthrough paper by Costanza and colleagues that estimated the monetary value of all global ecosystem services, catapulting natural capital into the spotlight [20]. Since then, research surrounding natural capital has continued to evolve, giving rise to a new vocabulary, shaping the discipline of ecological economics, and inspiring the journal Ecosystem Services [23]. What was originally a concept limited to academic study has expanded into a dynamic and diverse policy and decision-support tool for environmental management [28,29,52], and a shared language used by economists, policy-makers, scientists, statisticians, and civil society [22]. 
Adopting a natural capital lens reveals how the environment is connected to socio-economic systems through the valuable services it provides to people. This is conventionally depicted as the cascade model (Figure 2 [53]) which was originally devised to show how biodiversity, ecosystem services, and human well-being were linked. By adapting the cascade model to encompass natural capital stocks—including biodiversity-the model can be used to link stocks, interactions, and processes in the natural world (ecosystem functions), flows, benefits, and values. This is a simplified model and does not include the feedbacks within the system, but it can provide useful knowledge from the abstract complexity of socio-economic interactions and dependencies on the environment [53].

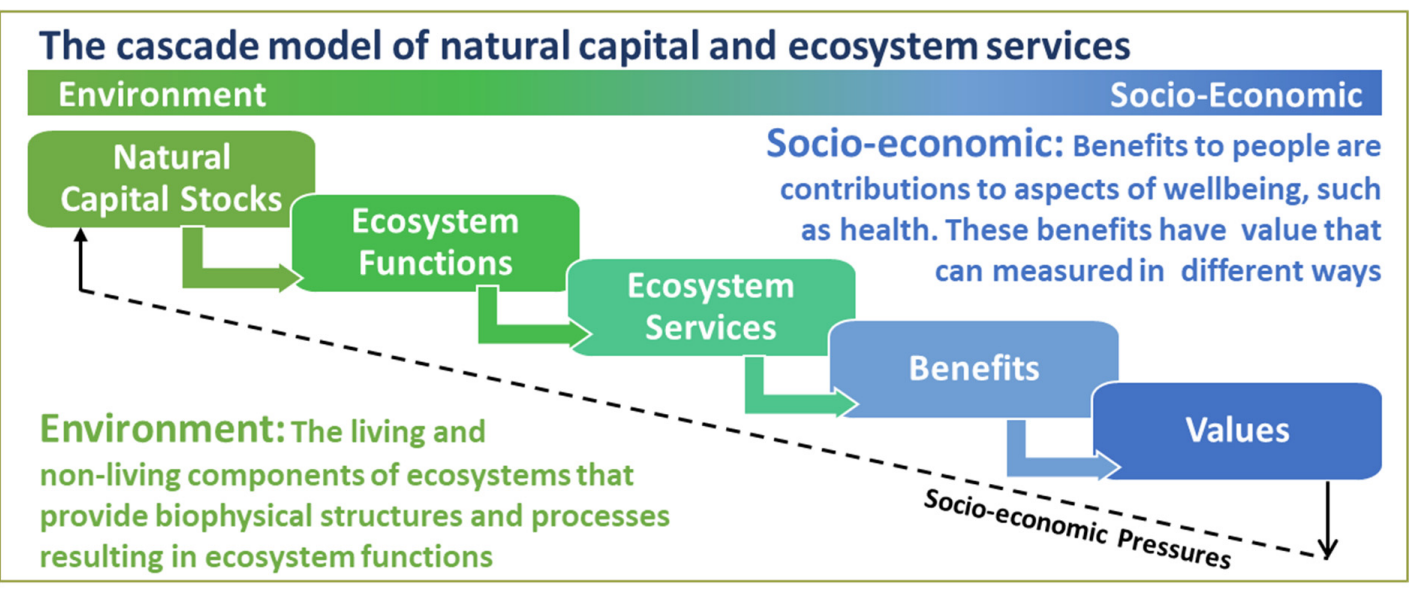

Figure 2. A simplified cascade model of natural capital that depicts how natural capital gives rise to ecosystem services that provide benefits to people and can be attributed value. Those values create socio-economic pressures and inform management decisions, connecting people back to the environment in a bidirectional relationship. Model adapted from [53].

Numerous organisations and initiatives are dedicated to promoting the natural capital concept including the Capitals Coalition (formerly Natural Capital Coalition (NCC)) [54], The Economics of Ecosystems and Biodiversity initiative (TEEB) [55], and the UN System for Economic and Environmental Accounting (SSEA) [56]. The concept has achieved a broad reach with members of the Capitals Coalition spanning high-level policy groups, NGOs, and private sector actors (including multinational industries). Within these initiatives are more specialised areas of activity. One TEEB sub-initiative explores agriculture and food systems (TEEB Agrifood), spanning the complexity of "eco-agri-food systems." This systems approach connects the economy to biodiversity, ecosystems, and livelihoods, using a framework of stocks, flows, outcomes, and impacts to describe biological production systems and the multiple services they provide. It includes brief mentions to competing biomass production for bioenergy and bio-plastics-bioeconomy-related demands-but does not yet draw the connection to the bioeconomy as a sustainability concept, or to related themes [57].

\subsection{Environmental Framings of the Bioeconomy and Natural Capital}

The bioeconomy and natural capital concepts are anthropocentric; they represent how people benefit from, use, and depend on biological systems, crafting new metaphors for the interactions and dependencies between people and the environment [52,58]. These metaphors shape how the environment is viewed from their respective vantage points, informing their underlying philosophy of environmental degradation and unsustainable practice, and how these problems can be resolved. Here we consider the environmental framings within each concept in turn.

The bioeconomy concept encompasses several different narratives concerning the environment that exist along a spectrum from the sole provision of private commodities to the simultaneous basket of public goods derived from nature $[8,45]$. A dominant narrative, aligned with the "bioresource" 
vision described by Bugge [8], adopts a utilitarian and resource economics stance that states that the environment provides renewable, biological resources that should be used in an efficient way to maximise human welfare [33]. These resources include biomass, biologically-mediated processes, and innovative bioproducts-that may or may not rely on high-tech bioscience applications-but ultimately depend upon ecosystem functioning, e.g., agroecosystems, to be fully realised [41,45]. An opposing "rival" narrative, or sometimes termed "agroecology" or "bioecology" vision, frames the environment as biological systems that produce numerous, simultaneous benefits that act as economic public goods and so management decisions should reflect this overall basket of services, rather than single-service outputs [8]. A separate study identified three main themes in the bioeconomy literature: (1) environmental sustainability as a challenge to rise to, (2) as a required standard that must be met, and (3) as a co-benefit that accompanies economic growth [11]. The range of competing environmental framings exemplifies the "shades of green" of the bioeconomy and its environmental sustainability contributions $[10,14,47]$.

The bioeconomy emphasises the socio-economic improvements made possible by using bioresources and associated biotechnology and how this can address environmental sustainability shortcomings under the economic status quo. Environmental degradation is framed as the reliance on non-renewables, especially fossil fuels, and the inefficient use of resources that creates negative externalities such as waste and pollution. The bioeconomy argues this degradation may be addressed through more efficient use of biological resources, enabled through biotechnological capabilities [6]. However, the interactions between the bioeconomy and nature are bidirectional; a growing bioeconomy will also apply pressure upon the environment [12]. These pressures manifest as the conflicts of competing resource demands to achieve food security, energy security (the food versus fuel debate), and a supply of homogeneous, high-quality bioresources $[17,41,59]$. The bioeconomy will emerge as part of a globalised system of value chains that connect spatially isolated ecosystems as consumers in one area create demand for bioresources produced elsewhere [60]. The combination of growing demand and the spatial decoupling of production and consumption of bioresources reconfigures the pressures socio-economic systems place upon the environment. A sustainable bioeconomy pursues a balancing arrangement between bioresource production and consumption on one hand, and the resulting environmental pressures and ecological limitations on the other.

The natural capital approach argues that all socio-economic systems are embedded within the environment and so a healthy and functioning environment is essential for the service flows that contribute to the welfare improvements, capabilities, and freedoms that people enjoy $[22,30,61]$. A healthy, resilient, and functioning environment is ultimately dependent on its natural capital asset base. A subset of these environmental building blocks are considered "renewable" natural capital—those which can self-maintain or replenish over relatively short timescales—the consumption of which is permissible so long as it does not exceed the natural rate of replenishment [22]. So long as socio-economic systems do not exploit ecosystems at a rate greater than they are able to self-maintain, environmental degradation, and the loss of ecosystem functions, can be prevented. Environmental degradation and biodiversity loss are thus the product of the systematic failure to account for only a subset of services-typically provisioning services at the expense of regulating and cultural services-and management decisions targeting single-service outcomes rather than maintaining a healthy natural capital asset base from which those services flow [28,62].

The distinction between the terms ecosystem services (flows) and natural capital (stocks) is an important point of clarification in the natural capital concept that is often lost in application [63]. Ecosystem services contribute to human wellbeing and the economy-they are explicitly anthropocentric and dependent on human demand [52] — but are a downstream product of ecosystem functions, produced from natural capital stocks (Figure 2), and realised through interactions with human and manufactured capital [22,64]. Management decisions and environmental pressures operate upon natural capital stocks, rather than the flow of ecosystem services, and it is important that this distinction is not lost when objectives focus on ecosystem service outputs $[62,65]$. 
Natural capital theorists have built upon, and expanded, this environmental framing. The term "critical natural capital" refers to natural capital stocks that are poorly substitutable by technology or other forms of capital meaning that they should be considered irreplaceable and their consumption cannot be justified $[52,61,66,67]$. This is aligned with the strong sustainability paradigm that not all forms of capital can be assumed as substitutable (as opposed to weak sustainability that states all capitals are fully substitutable) [61]. A second principle, the aggregate natural capital rule, argues that so long as the aggregate of natural capital assets is non-decreasing, losses in some stocks can be compensated by gains elsewhere [68]. So long as the critical natural capital base is maintained, and aggregate natural capital stocks are non-decreasing, environmental degradation can be prevented.

These guiding principles of environmental sustainability appear straightforward at first glance but are complex to implement effectively. For any context, we do not know which natural capital assets are "critical" to the functioning of an ecosystem, which necessitates caution. How to aggregate natural capital stocks that differ in measurement, quality, function, and perceived value, and how to make valid comparisons across scales, are ongoing challenges to applying the natural capital approach [52,68]. Due to these challenges, while the overarching framing of the environment is consistent, there is no singular "natural capital approach" that is appropriate for every situation and context. Instead, flexible frameworks that adopt steering principles of efficiency, equity, and sustainability are promoted as best-practice when using the natural capital concept for informed decision-making [30,52]. The natural capital approach is a powerful tool to interrogate the relationships between people and nature, but the complexity of its application can be a barrier to its implementation.

\subsection{Uniting the Bioeconomy and Natural Capital - An Integrated Cascade Model}

The bioeconomy and natural capital concepts share the principle that environmental resources are key to a stable economy and a fulfilled, healthy society. The dominant narratives of the bioeconomy seek novel bioresources and more efficient use of traditional bioresources that are provided from the environment as feedstocks that power the bioeconomy machine [7,8,41]. This is aligned with the set of ecosystem services termed "provisioning ecosystem services", and have been labelled as such [69,70]. The rival narrative or "bioecology" vision argues that the basket of public goods sourced from biological productive systems should be considered as part of the bioeconomy, in conjunction with provisioning services $[8,45]$. These public goods, such as carbon storage, nutrient recycling, and cultural landscapes, fall under the classifications of regulating and cultural ecosystem services [22]. The natural capital concept is grounded on the benefits sourced from the full range of services-provisioning, cultural and regulating - that have value to people but may be lost due to socio-economic pressures operating upon their underpinning natural capital [62]. As only a subset of those services are routinely valued or monetised, cost-benefit analyses fail to account for all benefits derived from nature, leading to sub-optimal management decisions. There is a danger that the predominant bioeconomy vision falls into the same trap, adopting a narrow focus on maximising provisioning service flows without considering other co-benefits, or the dependent natural capital asset base.

Broadly, the bioeconomy considers the environment as an opportunity of unrealised benefits whereas the natural capital approach presents the environment as the necessity of unrecognised benefits. Both groups of services, the unrealised and the unrecognised, are valuable and should be accounted for in sustainable development pathways. The "agroecology" or "bioecology" narrative has some resemblance to the natural capital approach in this respect but retains the language of public goods leaning towards the traditional economic lens and retaining a focus on service flows, rather than the asset base $[8,45]$. A social-ecological systems framework proposed by de Scutter touches upon the combination of private commodities (provisioning services) and public goods (regulating and cultural services) that contribute to the bioeconomy, but their framework does not draw the connection to ecosystem service classifications or the natural capital approach [12]. As such, this natural capital approach serves as a complementary tool that considers the broad spectrum of bioeconomy narratives 
to better understand the ecosystem services they emphasise, the implications for natural capital stocks, and the application of related methods to bioeconomic activities.

The natural capital approach shows that these narratives exist along a spectrum, from a narrow focus on only a single provisioning service-monoculture biomass production-to the broad recognition of the full basket of environmental services-including regulating and provisioning services-derived from biologically productive systems. The bioeconomy literature emphasises new economic opportunities, business models, value chains, and the efficient use of bioresources, focusing on the socio-economic end of the cascade model: the "downstream" benefits, values and monetisation yielded from ecosystem services. A revised cascade model is shown in Figure 3 that integrates these bioeconomic themes into the natural capital framework, expanding the view to include the "upstream" dependencies upon ecosystem functioning. It also incorporates the bidirectional relationship between ecosystems and the bioeconomy-the impacts that a realised bioeconomy will have upon the environment, shifting pressures upon natural capital stocks in pursuit of increased, high-value, bioresource flows.

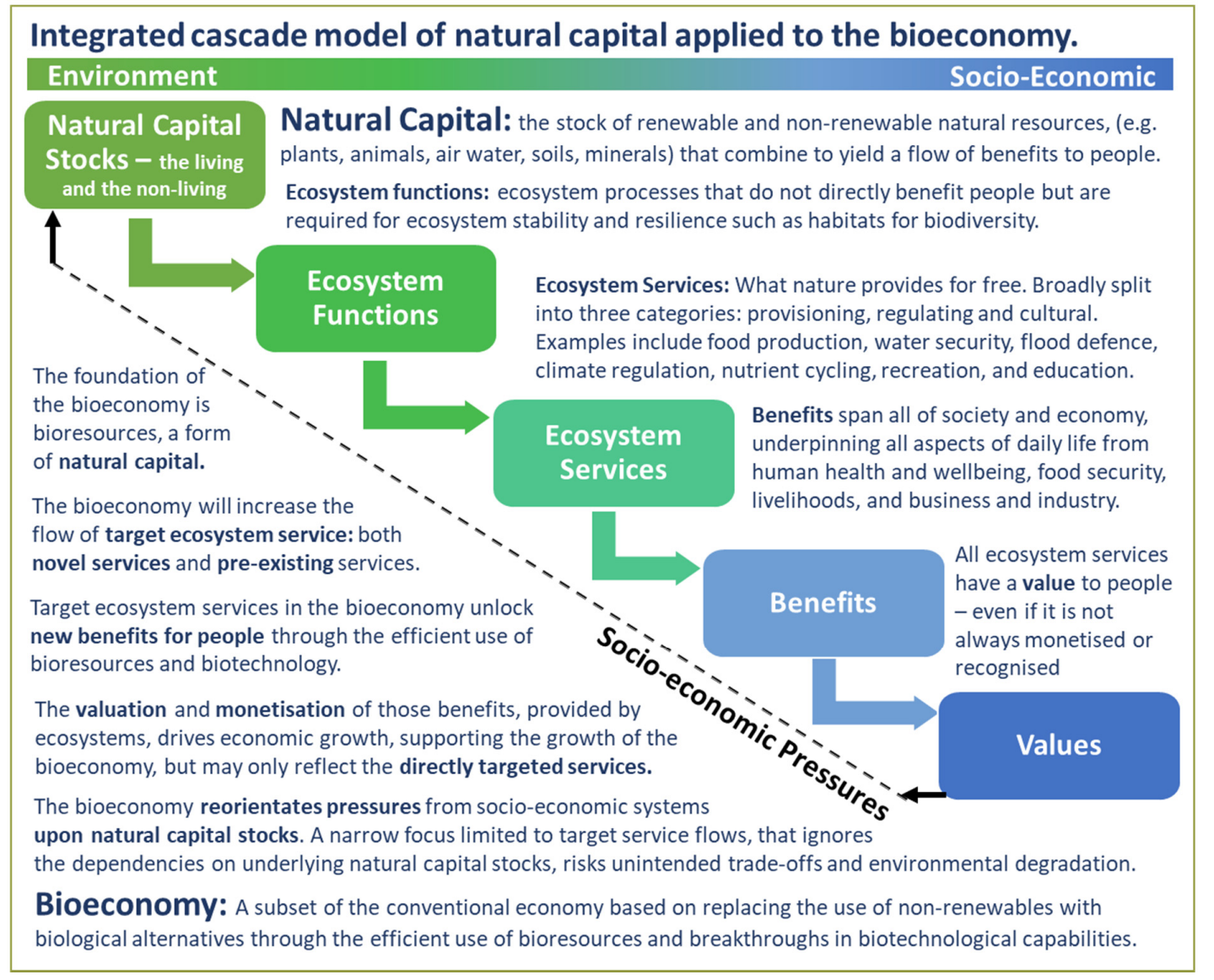

Figure 3. An integrated cascade model of the bioeconomy concept (lower left) and natural capital (upper right) based on the original by [53]. The natural capital cascade provides a framework to understand how the bioeconomy is fuelled by benefits provided from natural systems while also reorientating pressures upon those systems. Management decisions targeting the maximisation of a narrow subset of ecosystem service flows in the quest for a fully realised bioeconomy are in danger of overlooking essential underpinning natural capital stocks and ecosystem functions.

This reasserts that bioeconomy-mediated pressures are motivated by desirable ecosystem service flows, but act upon natural capital stocks, creating a mismatch between management decisions and impact pathways that could have unintended and far-reaching negative impacts upon ecosystem 
function. This necessitates a systems approach to environmental sustainability in the bioeconomy that accounts for the wider range of services provided from nature-all of which have value-and can ensure that broader environmental benefits are represented in bioeconomy discussions. The natural capital approach creates this link, providing the terminology, classification system, and flexibility to bring together competing bioeconomy narratives in a systems approach, recognising all services but allowing for weightings based on perceived value. Opportunities to support this linkage already exist, including the TEEB Agrifood framework of stocks, flows, outcomes, and impacts of eco-agri-food systems, which recognises both the economically visible and invisible services [57]. The emergent bioeconomy will create new resource demands upon such eco-agri-food systems that must be accounted for in this framework, but currently the two ideas remain fragmented.

\section{Natural Capital and the Cornerstones of a Sustainable, Future Bioeconomy}

The previous section explored the theoretical integration of the natural capital and bioeconomy concepts. We now examine how the natural capital concept can aid the development of a future, sustainable bioeconomy.

In 2016, 37 experts from the International Advisory Committee for the Bioeconomy published a commentary piece in the journal Nature proposing five principles to advance the bioeconomy and contribute towards the SDGs [34]. The article has since been well-cited by other literature exploring the sustainability of the bioeconomy suggesting these principles have been influential within the field [36,60,71-73]. The five cornerstones can be summarised as: research collaborations; measurement; multilateral policy linkages; education, knowledge and skills; and research and development support programmes. The commentary article is brief but does include a reference to natural capital: "A global bioeconomy must rebuild natural capital and improve the quality of life for a growing world population". This outlines that stewardship and appropriate management of natural capital are desirable outcomes of a sustainable bioeconomy. We explore these five cornerstones from a natural capital perspective by using them as a scaffold around which to question the complementarities and divergences between the two concepts.

\subsection{Cornerstone 1: International Collaborations between Governments and Public and Private Researchers}

The bioeconomy spans multiple disciplines, sectors, and industries, connecting international regions and value-chain actors. Research within the bioeconomy must reflect its interdisciplinary and interregional characteristics to achieve its environmental and economic sustainability aspirations. The dominant motivations and resulting narratives of the bioeconomy lean towards an economic lens of growth, value addition, and job creation, while emphasising STEM research, biotechnological innovations, and their applications $[49,58,74]$. Social sciences have an important role exploring public acceptance, policy design, and social sustainability but are less represented in the literature [74]. Network analyses show that collaborations between disciplines and international research networks are already present, albeit dominated by wealthier regions with strengths in high-tech industry, e.g., USA, EU, and China $[8,69]$.

The natural capital concept is inherently multidisciplinary having emerged from ecology and environmental science through the incorporation of economic tools and language to better understand and communicate the relationships between people and nature [22]. Social sciences are also acknowledged for their role in identifying the values and preferences that people have regarding the environment and ecosystem services [23]. Research initiatives by organisations such as the Capitals Coalition, The Intergovernmental Science-Policy Platform on Biodiversity and Ecosystem Services (IPBES), and TEEB have adopted an international and collaborative approach that reflects how ecosystems transcend national boundaries and are relevant to all disciplines. However, there is evidence to suggest the natural capital concept remains clustered within highly specialised groups, dominated by wealthy, English speaking nations that may limit collaboration and bridging between clusters $[63,75]$. 
Both natural capital and the bioeconomy draw upon natural sciences and economics while striving towards a systems approach to untangling the socio-economic relationships with the environment. The natural capital approach has developed tools and language to consider these interdisciplinary and interregional relationships $[65,76]$, while also establishing international organisations that connect different actors together in a collaborative way to share knowledge, e.g., IPBES, Capitals Coalition. This cornerstone emphasises that the bioeconomy must create a similar research dialogue to optimise resource use and knowledge sharing. Organisations such as the Global Bioeconomy Summit and the Bioeconomy Strategic Working Group-under the EU Standing Committee for Agricultural Research (SCAR)-represent one pathway to achieve this [77,78]. In parallel to these initiatives, integrating a natural capital approach could unlock pre-existing, collaborative networks and their expertise regarding interdisciplinary environmental sustainability.

\subsection{Cornerstone 2: Measurement of the Bioeconomy's Development and Sustainability Contributions}

Currently, measuring the bioeconomy resembles familiar economic metrics such as GDP contribution and value creation. These metrics often rely on proxies because of limited data resolution; what is sufficiently "bio-based" to be counted under the bioeconomy, and what is not [73,79]? Environmental metrics have been used to monitor bioeconomy initiatives such as life-cycle analysis (LCA) and environmental foot-printing [70-81]. A review of wood-based bioproduct LCA studies concluded that only $20 \%$ of ecosystem services were represented in those analyses [70]. While standardised protocols for LCA are published, identification of system boundaries for bio-based products, data availability, and the selection of appropriate impact factors are all challenges when considering how to measure environmental sustainability impacts of the bioeconomy [70,81-83].

The natural capital toolbox contains a diverse range of methods including field data collection and analysis, GIS mapping, and statistical modelling [84]. Natural capital accounting can incorporate a range of accounts such as quantifying natural capital stocks; assessing the quality, attributes, and spatial arrangement of those stocks; identification of service flows; beneficiary mapping; valuation; and monetisation (where appropriate) [51]. The UN System of Economic and Environmental Accounting has published a standardised approach to national natural capital accounting that has been adopted by some national accounting programmes $[27,56]$. This can make use of historical data while also responding to new methodological advances, e.g., remote sensing [84]. Despite this range of tools, natural capital approaches still wrestle with the wicked problems of complexity and uncertainty of ecosystem function $[52,85]$. Overarching questions remain as to how natural capital stocks give rise to service flows, how the quality and attributes of stocks influence those service flows, and how different service flows interact [64]. This can make the approach appear daunting to implement but this challenge has not gone unrecognised, with guidance documents and case-studies freely available from organisations such as The Natural Capital Project [86].

The natural capital approach can formalise a system of measurement to understand the impacts and dependencies between the bioeconomy and the environment that complements other metrics as they emerge. Its foundation in natural sciences is a methodological strength that makes use of interdisciplinary methods, whereas the bioeconomy currently has a less established toolkit of its own but can leverage the legitimacy of well-regarded economic proxies. Emergent high-tech solutions can also be incorporated into both concepts such as remote sensing and statistical modelling, although harmonised data collection remains a limiting factor $[34,80]$. To achieve a systems approach, environmental metrics must complement and build upon specialised but narrow metrics such as water use or carbon footprint [80]. The natural capital concept provides such a systems approach by providing the scope to incorporate the full range of natural capital stocks and how they interact, the bidirectional pressures between socio-economic systems and the environment [53], the international dimensions of bio-based value chains and interregional ecosystem service flows, and the network of beneficiaries and suppliers of those services $[76,87,88]$. Complexity and uncertainty remain a challenge in realising this 
systems approach, for example in assigning boundaries to the bioeconomy and understanding which ecosystem functions should be prioritised in future research.

\subsection{Cornerstone 3: Linkages with Multilateral Policy}

The modern conceptualisation of the bioeconomy emerged in part due to economic policy documents in the early 2000s that generated widespread momentum and subsequent adoption [32,42,43]. Over 45 countries have a dedicated national policy for the bioeconomy [8,33], some of which have been updated and revised, such as the EU strategy 2018 update [44], suggesting the concept has retained relevance and interest. These policies skew towards countries with domestic strengths for high-tech biotechnological applications, and so may not yet incorporate traditional bioresource production systems [60]. The intersection of the bioeconomy with numerous, traditionally siloed sectors and departments including primary production, such as agriculture, fisheries, and forestry, and other environmental departments, such as climate, culture and heritage, make achieving policy coherence a challenge [89].

Policy-makers and governance actors have adopted the natural capital approach, including some binding commitments. Its key themes are included in several international, high-level policy and governance documents such as the inclusion of ecological accounting in SDG15 [90], the commitment to the restoration and accounting of natural capital in the EU Biodiversity Strategy 2030 and the EU Green Deal [91,92], and Aichi Target 2 for the inclusion of biodiversity value to national accounts [24]. Many high-level policy bodies are members of the Capitals Coalition, such as the EC and United Nation Environment Program, which suggests such organisations have been a successful tool for promoting policy adoption [54].

The bioeconomy has achieved broad policy inclusion over the past decade, but often as standalone national strategies, lacking established linkages to environmental, multilateral policy processes, such as the SDGs, the Paris Agreement, and Aichi biodiversity agreements [34]. The natural capital approach is a potential bridge that could connect the bioeconomy to environmental, multilateral policy as more formal, standardised accounting protocols for natural capital are mainstreamed across national reporting and the private sector $[51,56,93]$. The support for natural capital has been catalysed by a push from academia to promote it as a tool for policy-making alongside support from dedicated international organisations $[28,29]$. The bioeconomy does not yet have the same level of organisational or institutional support although this may be emerging through initiatives such as the Global Bioeconomy Summit [77]. Potential vehicles to solidify this natural capital-mediated bridge already exist such as the TEEB Agrifood initiative, which presents a systems-based policy support framework that emphasises the multiple services derived from eco-agri-food systems and promotes a holistic evaluation beyond economic production [57].

\subsection{Cornerstone 4: Education, Skills, and Knowledge}

This cornerstone refers to "an interdisciplinary approach that emphasises systems thinking, strategic planning and evaluating environmental, social and economic performance" when considering the education, skills, and competencies needed for the developing bioeconomy. As discussed under cornerstone 1 , the bioeconomy has created collaborations between disciplines but how these disciplines communicate and disseminate their research is important for achieving systemic change. The lack of a universal definition for the bioeconomy makes this challenging by allowing the concept to be moulded around the user's self-interest, creating different understandings of the bioeconomy [8,9], and thus the required knowledge and skills. The language of bioeconomy is evolving but often reflects underpinning motivations for economic growth, such as economic metrics, coupled with perceived associations of sustainability contributions that are not necessarily justified $[8,33]$. Associations with terms such as "green", "renewable", and "natural" — that may be linked to the "bio" prefix—demonstrate this, but are not always qualified, contributing to the "master narrative" criticism; a concept that has lost precise 
meaning $[10,15,45]$. These barriers for effective education and communication must be overcome to create the skilled workforce and informed society required to realise sustainable bioeconomy.

In contrast to the bioeconomy, the natural capital concept has created a precise vocabulary that has become commonplace across ecological economics and related disciplines [22]. This terminology is continually being expanded and refined as the understanding of ecosystem functioning changes [65]. This has proved to be a useful asset in bringing together different actors with the same set of terminology to apply alongside their expertise that can aid communication and knowledge sharing [23]. Natural capital has created a bridge between policy-makers, researchers, civil society, and the private sector that facilitates knowledge sharing and will continue to do so as natural capital is further mainstreamed into environmental decision-making [94]. The suite of tools outlined under cornerstone 3 are designed to be applicable to different contexts and scenarios, and to equip decision-makers with the necessary information to evaluate environmental management decisions $[29,95]$.

Education, communication, and training are required for the bioeconomy to achieve its sustainability ambitions that place the environment and the economy on an equal footing. The barriers to knowledge sharing can be partially addressed by leveraging the influence and resources of the natural capital approach. The established terminology of natural capital can address some of the challenges of the bioeconomy as a "master narrative." Furthermore, equipping bioeconomy decision-makers and practitioners with the natural capital toolbox to untangle the intersections between the bioeconomy and the environment is an additional asset for securing a sustainable, future bioeconomy. Providing the tools to effectively validate and communicate environmental sustainability contributions of bioeconomic activities is one of the capabilities needed to secure this cornerstone. Social media networks involving natural capital have already been observed as a communication tool [63], and the rise in online learning opportunities such as the Stanford-based Natural Capital Project provide additional resources and lessons learned for the bioeconomy as it develops [86].

\subsection{Cornerstone 5: Support for Research and Development Programmes}

The bioeconomy requires investment in terms of finance, labour, and resources to develop and deploy new technologies and solutions for environmental sustainability challenges. Pilot projects and a subsequent scale-up of new biotechnology are needed to demonstrate the potential of new innovations and their contributions towards the bioeconomy's objectives $[96,97]$. There is a limited amount of investment available for the bioeconomy that should be allocated efficiently to areas of special interest or potential for the greatest impact. Identifying those opportunities requires aspects of all four prior cornerstones through interdisciplinary expertise and perspectives, appropriate measures of change, supporting and enabling policy, and knowledge sharing and education.

The natural capital perspective can enable new investment opportunities and strengthen the allocation of already existing investment streams. Firstly, it provides environmental metrics and measures of change that demonstrate sustainability contributions from bioeconomy projects that can feed into evaluating and allocating support programme resources [28]. Natural capital's increasing adoption within other environmental policy, such as the SDGs and the EU Green Deal, lends a legitimacy to the integration of natural capital alongside the bioeconomy $[90,91]$. Natural capital demonstrates additional value of bioeconomy projects, both in monetary terms and other forms of value, that are not represented in conventional analysis, creating a holistic, multidimensional lens for assessment [61]. This value of natural capital has already been adopted by private and financial sectors as demonstrated by the European Investment Bank's "Natural Capital Financing Facility" [98], the World Bank's "Genuine Savings" metric [99], and the growing push for "The business case for biodiversity", with numerous global assessments suggesting that services derived from nature provide $2-3$ times the global GDP $[25,26]$. Bioeconomic projects that can demonstrate how they contribute to enhancing and conserving natural capital-in parallel to social and economic benefits-can unlock otherwise unavailable investment streams for research, development, and deployment. 


\section{A Policy Case Study: Applying a Natural Capital Lens to the EU Bioeconomy Strategy}

We now present a case-study examination of the EU Bioeconomy Strategy first published in 2012 and updated in 2018 as viewed through a natural capital lens. For a broader review of the strategy and its formation, see $[7,32,100]$. We examine the elements of the natural capital concept represented in the strategy and then present opportunities and recommendations for further integration that could unlock policy synergies and progress for sustainability objectives.

\subsection{The EU Bioeconomy Strategy 2012}

The original bioeconomy strategy contained three key themes: investment in research, innovation and skills; reinforced stakeholder engagement and policy interaction; and the enhancement of markets and EU competitiveness [40]. Previous analysis has argued that economic aspirations of the strategy dominated over environmental or social considerations [58]. The strategy included an acknowledgement of environmental challenges, both climate change and biodiversity loss, and aspirations to address them via the bioeconomy's development, but also states that "the bioeconomy is not a niche area-it is about jobs and growth" (p. 4), centring the economic motivations underpinning the strategy.

When viewed through a natural capital lens, the strategy focuses on marketable (economically visible), provisioning ecosystem services (although they are not labelled as such), the benefits they can provide (through replacing non-renewables in industry and creating new jobs), and emphasises their perceived, potential value (creating new markets, economic growth, and competitiveness). For example, when referring to biotechnology, fisheries, and the marine sector, the strategy states that $90 \%$ of marine biodiversity is "unexplored" and the "unexploited potential of the sea" (p. 36) could result in $10 \%$ annual growth for the sector [40].

The strategy focused on producing sufficient food, biomass, and biomaterials-provisioning ecosystem services-to meet the demands of food security and the growth of bio-based industry, such as bioenergy and biorefineries [69]; typified as the "bioresource vision" of the bioeconomy [8]. Climate mitigation was also present as an underlying driver and carbon storage was one of the few regulating services included in the strategy, although ecosystem service classification was absent. What could be labelled as regulating and cultural ecosystem services were acknowledged as "public goods" from multifunctional agricultural and forestry systems, but the strategy's goal was to maintain these "public goods" while maximising the flow of target, desirable biomass. A passage from the strategy's working document related to forestry demonstrates this: "An important goal is to mobilise more wood in appropriate areas while safeguarding biodiversity and other public goods delivered by forests" (p. 31). The document listed these public goods to include soil fertility, water retention, biodiversity habitats, and vibrant landscapes that are perhaps more visible in the forestry systems as they are not typically competing with the demands of food production [18]. Overall, the strategy leant towards a predominantly single-service lens, aligned with the conventional economic system, with the co-benefit of climate mitigation and other environmental "public goods."

The term "natural capital" was absent from the original EU strategy and its action plan, while the term "ecosystem service" was sparingly mentioned, without classification or specificity, and used when referring to non-target services provided simultaneously by primary production ecosystems. The desire to increase the provision of bio-based raw materials "without compromising ecosystem services" (p. 29) was included under the heading of enhancing bioeconomy-related markets. This implies that biomass provision was not considered an ecosystem service itself, and that these other referenced ecosystem services were viewed as outside the remit of the bioeconomy. While this hinted towards an appreciation of ecosystem trade-offs, it failed to expand on what is a "compromised ecosystem service", which could refer to decreases in the flow of a single service, decreases in the aggregate of multiple services, changes to the distribution of benefits, or losses of underpinning ecosystem functions. Furthermore, the statement did not explore the impact pathways for how management decisions to enhance target provisioning services could create these trade-offs, compromising secondary services. Soils were one 
of the few natural capital stocks articulated as being directly manipulated by management decisions through changes to nutrient status, salinity, and fertility, with consequences for service flows such as carbon storage and crop production, highlighting the pressures the emergent bioeconomy would place on the environment $[15,38]$. Despite appreciating that growing demands for ecosystem services may act antagonistically, for example, food provision and biomass production for fuels [17,41], this was not expanded upon to capture the range of underlying natural capital stocks impacted by the shifting socio-economic pressures of the bioeconomy. Instead this framing "short-circuits" the cascade model by connecting human demand, values, and pressures straight to ecosystem service flows, bypassing the underpinning natural capital foundation.

Other environmental considerations regarding EU bioeconomy markets and competitiveness included the creation of LCA approaches for bio-based products, voluntary standards, certification and eco-labelling schemes, and environmental footprinting methods. The intention to design tools that examined and qualified the environmental sustainability of bio-based products and industries was notable, but they were regarded as aspirational rather than a reality, requiring further research and development before they could be deployed. This is consistent with ongoing challenges for creating these metrics such as assigning life cycle boundaries [81], selecting appropriate impact factors for ecological impacts $[83,101]$, and considering the broad range of environmental impacts rather than one-dimensional evaluations $[70,80]$.

\subsection{The EU Bioeconomy Strategy Update 2018}

The updated EU Bioeconomy Strategy, published in 2018, features more environmental aspects following criticism of the original's dominant economic focus $[58,102]$. The opening section emphasises the challenges of "ecological degradation" and "ecological boundaries" with a "respect for the ecological limitations of the planet" (p. 1). The commitment to environmental sustainability is echoed by the depiction of the EU's bioeconomy pathway as "economically viable with sustainability and circularity in the driver's seat" (p. 3), while simultaneously harkening back to economic motivations [7].

One of the most noticeable changes in the 2018 update from a natural capital perspective is a new definition of the bioeconomy that includes "all sectors and systems that rely on biological resources, their functions and principles. It includes and interlinks land and marine ecosystems and the services they provide" (p. 1) (emphasis added). Therefore, it can be argued that under this definition, any ecosystem function that contributes to an economic sector-including regulating and cultural services-is included within the bioeconomy, rather than as a disparate co-benefit to be secured or trade-off to be mitigated. This extends the bioeconomy umbrella to all ecosystem services that support an economic sector, yet the strategy does not build on this extended flexibility and scope, retaining a familiar three-way focus on food security, the provision of biomass, and climate mitigation.

The 2018 update does not reference "natural capital" despite its inclusion within other predating EU environmental documents, such as the commitment to "protect, conserve and enhance" natural capital in the EU's 7th Environmental Action Plan, and the adoption of natural capital terminology within the European Environment State and Outlook Report [103,104]. The update does revise some terminology and language compared to the original. It states that natural resource management should "avoid ecosystem degradation, restore and enhance ecosystem functions" (p. 5). It is notable that "ecosystem function" is used rather than ecosystem service, indicating that direct human benefit or utility is not a requirement for implementing measures that prevent ecological degradation. This may represent an appreciation for the underlying ecosystem functions that support and give rise to target ecosystem service flows for the bioeconomy and, thus, are essential for ensuring long-term, sustainable service provision [65]. However, the language remains unrefined and vague, without measurable indicators or targets. "Degradation" may refer to several different things, including the loss of species, service flows, or functions; or changes to the quantity, quality, or spatial arrangement of capital stocks. "Restore and enhance functions" suffers from a similar problem as it does not expand on what the 
reference condition for comparison should be, or what the target goal should look like. While this is context-specific, guidelines or principles to inform these goals of ecological restoration are missing.

One of the three key action areas of the 2018 update is titled "Understand the ecological boundaries of the bioeconomy" which clearly recognises that there are ecological limitations for the bioeconomy-and perhaps borrows language from the popularised planetary boundaries concept of sustainability [1]. These ecological boundaries are not defined but involve the sustainable maximisation of biomass extraction that can also "enhance the full-range of ecosystem services" (p. 10) and "reinforce resilience and enhance biodiversity" (p. 10). Again, it is not clear what is meant by "enhance" or "reinforce" but it echoes a familiar desire to maximise the efficiency of what people receive from nature-finding out how target provisioning services, and their downstream benefits and values, can be maximised without negative consequences for other ecosystem characteristics. The 2018 update references the benefits of "biodiversity-rich ecosystems" (p. 12) for primary production, with a specific reference to pollination. This may be inspired by high-profile research publications concerning agriculture's dependence upon [105], and monetary value attributed to [106], pollination services, and an influential global assessment of pollinators, pollination, and food production [107]. The specific inclusion of this non-provisioning service and the recognition of biodiversity's importance is encouraging but remains a single example that emphasises the ecosystem service-pollination - that is dependent upon numerous natural capital stocks, of which only one - the biodiversity of agroecosystems—is mentioned [62].

The ecological boundaries section of the updated strategy contains another element of complementarity between the natural capital and bioeconomy concepts. To better understand these boundaries, the strategy refers to acquiring data, information, and systematic analysis to reveal the "status and resilience ... of ecosystems and biodiversity" (p. 10). There is an appreciation that these ecological data are not well known, and that addressing these knowledge gaps regarding biodiversity and nature is important for managing the biologically productive systems the bioeconomy depends upon. This call for better data collection and environmental knowledge is analogous to the exercise of natural capital accounting which takes stock of nature's assets to provide a foundation for informed decision-making [51,93]. It includes attributes regarding quality and spatial arrangement of those stocks and covers local to national to global scales $[29,95]$. Despite ongoing work regarding natural capital accounting in the EU that predates the publication of this updated strategy, it is noticeably missing from this section of the strategy [108].

\subsection{Future Policy and Recommendations}

The 2018 update to the initial 2012 EU Bioeconomy Strategy contains a patchwork of elements aligned with the natural capital concept but is missing some aspects that could be developed further. A bioeconomy that embraces the natural capital framework could benefit from the lessons learned within the natural capital approach and unlock policy synergies regarding the relationships between socio-economic systems and the environment. The following section outlines some recommendations and opportunities to incorporate the natural capital lens into the future bioeconomy strategy in the EU.

\subsubsection{A Shared Language}

Firstly, the language of natural capital can clarify the intent behind terms such as biological resources, bioresources, and natural resources. Distinguishing between natural capital, ecosystem functions, and ecosystem services can refine objectives and better describe the relationship between these ecological constructs and the development of the bioeconomy. For example, considering the growing market for wood-based bioproducts and the forestry sector, the stand of trees is a natural capital stock, the production of new wood biomass is an ecosystem function, and the provision of harvested timber-realised through combinations of human, manufactured, and natural capital-is an ecosystem service [37]. This distinction resolves ambiguous meanings and aids the identification of appropriate management levers through a proposed impact pathway. As management changes manipulate natural capital stocks, either in quantity, quality, or spatial arrangement, rather than the 
flow of functions or services that are impacted indirectly, it is important that this clarity is present for informed decision-making [62]. The presence of ecosystem service and ecosystem function terminology in the 2018 update is an encouraging sign. However, the vocabulary is incomplete and at times applied ambiguously, as in the case of the focus on biodiversity in relation to pollination in bio-based value chains. The value of pollination is implied but is not related to the ecosystem service framework or acknowledged as a direct contribution of value to the bioeconomy. While there is an appreciation that biodiversity can contribute to service flow, the action plan does not refer to management options that manipulate underlying natural capital stocks to support biodiversity, such as suitable habitat creation, landscape heterogeneity, or resource availability [62].

\subsubsection{A Harmonised Bioeconomy}

A second opportunity is the creation of a framework that brings together the fragmented mosaic of bioeconomy visions [8]. The revised strategy already expands the definition of the bioeconomy to include ecosystem services from land and marine ecosystems and "biological functions" that contribute to bioeconomy sectors. This definition cements the view that regulating and cultural services are included under the bioeconomy umbrella. Whether the use of "biological function" refers to ecological functions as represented in the natural capital concept is unclear. While this new definition places regulating and cultural services within the bioeconomy, the linkage to the original strategy's depiction of "public goods" from multifunctional, agricultural, and forestry systems must be further elucidated.

This updated definition provides the scope to embrace the natural capital lens, acting as a bridge between the "dominant" and "rival" imaginings of the bioeconomy $[8,45]$. This framework could encompass the full basket of services provided from ecosystems-as depicted by the rival or agroecology vision-and also be weighted towards services attributed high value, such as target provisioning services-aligned with the bioresource vision. This approach could bring together advocates of different "narratives," such as civil society groups who promote the agroecology approach [109] and private sector and policy actors who promote more biotechnological narratives [8,102]. By creating a shared understanding, precise vocabulary, and unifying foundation to explore the concept, the natural capital lens may also address some of the criticisms of the bioeconomy as a "master narrative" with "shades of green", moving towards a platform for collaboration and knowledge sharing $[10,45,47]$.

\subsubsection{Improved Indicators, Metrics, and Measures}

Thirdly, the natural capital approach and natural capital accounting can provide useful metrics and indicators for the bioeconomy. A significant portion of the 2018 update concerns respecting the "ecological boundaries" of the bioeconomy and the importance of knowledge sharing, data collection, and analysis to better understand these boundaries. Natural capital accounting has a proven record of applying approaches highlighted in the strategy such as remote sensing [84], assessment at the local or regional scale [65], creating national-level accounts [110], global valuations [20], and assessing change over time [88]. Natural capital accounts are increasingly valued for supporting policy decision-making $[29,93,111]$. Building upon a robust set of natural capital accounts can facilitate the creation of minimum standards, environmentally sound certification schemes, and demonstrable measures of change that ensure that commitments to "enhancing and protecting" natural capital are being adhered to. Mapping ecosystem services can also shine a light on environmental justice and the flow of valuable benefits within the bioeconomy between spatially separated people and regions $[76,88]$. The facilitation of local-level bioeconomy initiatives and "more proportionate sharing of the benefits" (p. 11) [44] are key aspirations of the EU bioeconomy. Natural capital tools can value and map those benefits for more economically just and equitable outcomes $[52,88]$.

\subsubsection{Policy Synergy and Coherence}

The adoption of natural capital principles within the bioeconomy would align the strategy with other environmental EU policies to create a more integrated and united environmental policy 
approach [112]. Natural capital has been adopted in EU policy previously, for example in the 7th Environmental Action Plan [103], and more recently, in the EU Green Deal which states that all EU policy moving forward must "contribute to preserving and restoring Europe's natural capital" (p. 13) [91]. The EU Biodiversity Strategy for 2030 includes similar commitments regarding investment in natural capital and natural capital accounting [92]. This adoption of the natural capital concept will have implications for all future EU policy, including those sectors particularly central to the bioeconomy such as agriculture, forestry, and fisheries. The broad adoption of the natural capital lens in policy represents a shift in the conceptualisation of peoples' relationships with nature that the bioeconomy should mirror to maintain policy coherence and create synergy. Bioeconomy-related policies often stipulate that sustainability is a priority but do not identify what this means practically. Natural capital could provide knowledge that identifies impacts and dependencies between the environment and bioeconomy development pathways, and policy support tools to facilitate this synergy already exist, such as the TEEB Agrifood framework [57].

\subsubsection{A Flexible and Adaptable Tool for Decision-Making}

Finally, adopting a natural capital lens on the bioeconomy ensures that the concept remains flexible, adaptable, and responsive to changes to environmental approaches to sustainability. The modern conceptualisation of the bioeconomy is still emerging with an uncertain trajectory towards new biotechnological capabilities, resource demands, and public acceptance [9]. The bioeconomy will realise new ecosystem services, such as by-products of conventional primary production or the use of waste streams [41]. The natural capital concept can incorporate these new services and their values both retroactively and for future analysis to be used as a decision-support tool [95]. A bioeconomy strategy that adopts the natural capital framework is responsive to changes in ecosystem service demand, their respective values and valuation techniques, and shifting environmental impacts and dependencies of bio-based value chains. This allows for dynamic, responsive decision-making as the bioeconomy changes pressures on natural capital stocks that reorient the relationships between socio-economic systems and the environment $[29,95]$.

\section{Conclusions}

We have successfully applied a natural capital lens to the bioeconomy concept across three levels: an integrated cascade model, expert's cornerstones for a sustainable bioeconomy, and a case-study of the EU bioeconomy strategy. The natural capital concept and its associated methodological toolbox have the potential to play an important role in securing the bioeconomy's environmentally sound and ecologically conscious objectives. Despite a similar multidisciplinary background and growing influence within research and policy spheres, the integration of the two concepts has not been examined in this way previously. This study has shown that there are areas of overlap between the bioeconomy and natural capital concepts, but there remains scope for further integration across policy, research, and practice.

The current patchwork of environmental framings within the bioeconomy has led to fragmented understandings of how the bioeconomy intersects with ecosystems and nature. There are opportunities to operationalise the natural capital approach within the bioeconomy to address this fragmented sustainability landscape. The integrated natural capital cascade model serves as a mechanism to unite the unrealised and unrecognised services provided from the environment by ensuring that all of nature's services-the economically visible and invisible-are included in decision-making. By ensuring that both the unrealised and unrecognised services from nature are included in a holistic, systems-based approach to decision-making and policy design, the bioeconomy can avoid unintended trade-offs and environmental degradation. Furthermore, this can qualify the "shades of green" of bioeconomic activities and unlock policy-policy synergies relating to environmental decision-making and safeguarding nature. 
The bioeconomy concept is amorphous; constantly shifting and evolving as new research emerges and is subsequently adopted by bioeconomy-related actors. We cannot predict how the concept will continue to change, or how the shifting values and preferences of societies will shape its development. Therefore, this analysis represents the current state of the art understanding of how the bioeconomy intersects with the environment while acknowledging that some other understandings of the term "bioeconomy" may not be captured e.g., bioeconomic modelling or narrow, specialised synthetic biology applications. Research that builds upon the themes presented here must remain responsive to changes to the bioeconomy concept as it evolves. The same is true for natural capital as there is no universal natural capital solution to a given environmental problem, but instead a set of guiding principles that can inform decision-making. Care must be taken to consider the given context for deploying natural capital to a bioeconomic activity such as data availability and suitability, the particular environmental problem to be solved, and social context it operates within.

Future research can build upon this analysis by identifying appropriate case studies that move from the theoretical integration of these concepts towards applied and demonstrable examples. A challenge and limitation to achieve this is the siloed nature of research; a constellation of relevant studies within agricultural science, environmental science, sustainability science and the bioeconomy are likely ongoing but do not cross the boundaries between their respective clusters of expertise. This is echoed in the variety of appropriate methodologies that can be used to examine natural capital and the bioeconomy which span biophysical studies of ecosystems, social sciences and perceived values, monetary evaluations, economic analysis, and scenario modelling. Facilitating the dissemination of research across disciplines must be a priority for natural capital researchers. Evidence of these linkages is emerging as demonstrated by the adoption of some natural capital elements within the EU bioeconomy strategy. The breakdown of fragmented and siloed pockets of environmental sustainability expertise that moves towards an interdisciplinary and holistic approach is required for sustainable development that safeguards nature.

Author Contributions: Conceptualization, A.M.N, J.C.S., and C.O.; methodology, A.M.N, J.C.S., and C.O.; formal analysis, A.M.N.; investigation, A.M.N.; writing-original draft preparation, A.M.N.; writing-review and editing, A.M.N., J.C.S. and C.O.; visualization, A.M.N.; supervision, J.C.S. and C.O.; project administration, J.C.S. All authors have read and agreed to the published version of the manuscript.

Funding: This publication has emanated from research supported in part by a research grant from Science Foundation Ireland (SFI) under Grant Number 16/RC/3889 and is co-funded under the European Regional Development Fund and by BiOrbic industry partners.

Acknowledgments: We acknowledge the useful comments and discussion provided by C. Farrell. The graphical abstract was created using the BioRender online application.

Conflicts of Interest: The authors declare no conflict of interest.

\section{References}

1. Rockström, J.; Steffen, W.; Noone, K.; Persson, Å.; Chapin, F.S.; Lambin, E.F.; Lenton, T.M.; Scheffer, M.; Folke, C.; Schellnhuber, H.J. A safe operating space for humanity. Nature 2009, 461, 472-475. [CrossRef]

2. Raudsepp-Hearne, C.; Peterson, G.D.; Tengö, M.; Bennett, E.M.; Holland, T.; Benessaiah, K.; MacDonald, G.K.; Pfeifer, L. Untangling the environmentalist's paradox: Why is human well-being increasing as ecosystem services degrade? Bioscience 2010, 60, 576-589. [CrossRef]

3. IPBES 2019. Summary for Policymakers of the Global Assessment Report on Biodiversity and Ecosystem Services of the Intergovernmental Science-Policy Platform on Biodiversity and Ecosystem Services. IPBES Secreteriat: Bonn, Germany. Available online: https://ipbes.net/sites/default/files/inline/files/ipbes_ global_assessment_report_summary_for_policymakers.pdf (accessed on 23 August 2020).

4. Khanna, M.; Swinton, S.M.; Messer, K.D. Sustaining our Natural Resources in the Face of Increasing Societal Demands on Agriculture: Directions for Future Research. Appl. Econ. Perspect. Policy 2018, 40, 38-59. [CrossRef]

5. O'Neill, D.W.; Fanning, A.L.; Lamb, W.F.; Steinberger, J.K. A good life for all within planetary boundaries. Nat. Sustain. 2018, 1, 88. [CrossRef] 
6. Zilberman, D.; Gordon, B.; Hochman, G.; Wesseler, J. Economics of sustainable development and the bioeconomy. Appl. Econ. Perspect. Policy 2018, 40, 22-37. [CrossRef]

7. McCormick, K.; Kautto, N. The bioeconomy in Europe: An overview. Sustainability 2013, 5, 2589. [CrossRef]

8. Bugge, M.; Hansen, T.; Klitkou, A. What is the bioeconomy? A review of the literature. Sustainability 2016, 8, 691. [CrossRef]

9. Gawel, E.; Pannicke, N.; Hagemann, N. A Path Transition Towards a Bioeconomy-The Crucial Role of Sustainability. Sustainability 2019, 11, 3005. [CrossRef]

10. Hausknost, D.; Schriefl, E.; Lauk, C.; Kalt, G. A transition to which bioeconomy? An exploration of diverging techno-political choices. Sustainability 2017, 9, 669. [CrossRef]

11. Kleinschmit, D.; Arts, B.; Giurca, A.; Mustalahti, I.; Sergent, A.; Pülzl, H. Environmental concerns in political bioeconomy discourses. Int. For. Rev. 2018, 19, 41-55. [CrossRef]

12. De Schutter, L.; Giljum, S.; Häyhä, T.; Bruckner, M.; Naqvi, A.; Omann, I.; Stagl, S. Bioeconomy Transitions through the Lens of Coupled Social-Ecological Systems: A Framework for Place-Based Responsibility in the Global Resource System. Sustainability 2019, 11, 5705. [CrossRef]

13. Loiseau, E.; Saikku, L.; Antikainen, R.; Droste, N.; Hansjürgens, B.; Pitkänen, K.; Leskinen, P.; Kuikman, P.; Thomsen, M. Green economy and related concepts: An overview. J. Clean. Prod. 2016, 139, 361-371. [CrossRef]

14. Pfau, S.; Hagens, J.; Dankbaar, B.; Smits, A. Visions of sustainability in bioeconomy research. Sustainability 2014, 6, 1222-1249. [CrossRef]

15. Székács, A. Environmental and Ecological Aspects in the Overall Assessment of Bioeconomy. J. Agric. Environ. Ethics 2017, 30, 153-170. [CrossRef]

16. Sheppard, A.W.; Gillespie, I.; Hirsch, M.; Begley, C. Biosecurity and sustainability within the growing global bioeconomy. Curr. Opin. Environ. Sustain. 2011, 3, 4-10. [CrossRef]

17. Graham-Rowe, D. Beyond food versus fuel. Nature 2011, 474, S6-S8. [CrossRef]

18. Eyvindson, K.; Repo, A.; Mönkkönen, M. Mitigating forest biodiversity and ecosystem service losses in the era of bio-based economy. For. Policy Econ. 2018, 92, 119-127. [CrossRef]

19. Heimann, T. Bioeconomy and SDGs: Does the Bioeconomy Support the Achievement of the SDGs? Earth Future 2019, 7, 43-57. [CrossRef]

20. Costanza, R.; D’Arge, R.; De Groot, R.; Farber, S.; Grasso, M.; Hannon, B.; Limburg, K.; Naeem, S.; O’Neill, R.V.; Paruelo, J. The value of the world's ecosystem services and natural capital. Nature 1997, 387, 253-260. [CrossRef]

21. Barbier, E.B. The concept of natural capital. Oxf. Rev. Econ. Policy 2019, 35, 14-36. [CrossRef]

22. Costanza, R.; de Groot, R.; Braat, L.; Kubiszewski, I.; Fioramonti, L.; Sutton, P.; Farber, S.; Grasso, M. Twenty years of ecosystem services: How far have we come and how far do we still need to go? Ecosyst. Serv. 2017, 28, 1-16. [CrossRef]

23. Braat, L.C.; de Groot, R. The ecosystem services agenda: Bridging the worlds of natural science and economics, conservation and development, and public and private policy. Ecosyst. Serv. 2012, 1, 4-15. [CrossRef]

24. Millennium Ecosystem Assessment. Ecosystems and Human Well-Being: A Framework for Assessment Summary; Island Press: Washington, DC, USA, 2005; ISBN 1-59726-040-1.

25. Costanza, R.; de Groot, R.; Sutton, P.; van der Ploeg, S.; Anderson, S.J.; Kubiszewski, I.; Farber, S.; Turner, R.K. Changes in the global value of ecosystem services. Glob. Environ. Chang. 2014, 26, 152-158. [CrossRef]

26. OECD Biodiversity. Finance and the Economic and Business Case for Action. Available online: https://www.oecd-ilibrary.org/environment/biodiversity-finance-and-the-economic-and-business-casefor-action_a3147942-en (accessed on 21 July 2020).

27. Hein, L.; Bagstad, K.J.; Obst, C.; Edens, B.; Schenau, S.; Castillo, G.; Soulard, F.; Brown, C.; Driver, A.; Bordt, M.; et al. Progress in natural capital accounting for ecosystems. Science 2020, 367, 514-515. [CrossRef] [PubMed]

28. Guerry, A.D.; Polasky, S.; Lubchenco, J.; Chaplin-Kramer, R.; Daily, G.C.; Griffin, R.; Ruckelshaus, M.; Bateman, I.J.; Duraiappah, A.; Elmqvist, T. Natural capital and ecosystem services informing decisions: From promise to practice. Proc. Natl. Acad. Sci. USA 2015, 112, 7348-7355. [CrossRef]

29. Daily, G.C.; Polasky, S.; Goldstein, J.; Kareiva, P.M.; Mooney, H.A.; Pejchar, L.; Ricketts, T.H.; Salzman, J.; Shallenberger, R. Ecosystem services in decision making: Time to deliver. Front. Ecol. Environ. 2009, 7, $21-28$. [CrossRef] 
30. Reyers, B.; Selig, E.R. Global targets that reveal the social-ecological interdependencies of sustainable development. Nat. Ecol. Evol. 2020, 4, 1011-1019. [CrossRef]

31. Ehrlich, P.R.; Mooney, H.A. Extinction, Substitution, and Ecosystem Services. Bioscience 1983, 33, $248-254$. [CrossRef]

32. Patermann, C.; Aguilar, A. The origins of the bioeconomy in the European Union. New Biotechnol. 2018, 40, 20-24. [CrossRef]

33. Priefer, C.; Jörissen, J.; Frör, O. Pathways to shape the bioeconomy. Resources 2017, 6, 10. [CrossRef]

34. El-Chichakli, B.; von Braun, J.; Lang, C.; Barben, D.; Philp, J. Policy: Five cornerstones of a global bioeconomy. Nature 2016, 535, 221-223. [CrossRef] [PubMed]

35. Vainio, A.; Ovaska, U.; Varho, V. Not so sustainable? Images of bioeconomy by future environmental professionals and citizens. J. Clean. Prod. 2019, 210, 1396-1405. [CrossRef]

36. Ronzon, T.; Sanjuán, A.I. Friends or foes? A compatibility assessment of bioeconomy-related Sustainable Development Goals for European policy coherence. J. Clean. Prod. 2020, 254, 119832. [CrossRef] [PubMed]

37. Marchetti, M.; Vizzarri, M.; Lasserre, B.; Sallustio, L.; Tavone, A. Natural capital and bioeconomy: Challenges and opportunities for forestry. Ann. Silvic. Res. 2014, 38, 62-73. [CrossRef]

38. Helming, K.; Daedlow, K.; Paul, C.; Techen, A.K.; Bartke, S.; Bartkowski, B.; Kaiser, D.; Wollschläger, U.; Vogel, H.J. Managing soil functions for a sustainable bioeconomy-Assessment framework and state of the art. Land Degrad. Dev. 2018, 29, 3112-3126. [CrossRef]

39. D'Amato, D.; Korhonen, J.; Toppinen, A. Circular, Green, and Bio Economy: How Do Companies in Land-Use Intensive Sectors Align with Sustainability Concepts? Ecol. Econ. 2019, 158, 116-133. [CrossRef]

40. European Commission (EC). Innovating for Sustainable Growth: A Bioeconomy for Europe; EU Publications: Brussels, Belgium, 2012.

41. Lewandowski, I. Securing a sustainable biomass supply in a growing bioeconomy. Glob. Food Sec. 2015, 6, 34-42. [CrossRef]

42. OECD. The Bioeconomy to 2030: Designing a Policy Agenda; OECD Publishing: Paris, France, 2009; Available online: https://www.oecd-ilibrary.org/economics/the-bioeconomy-to-2030_9789264056886-en (accessed on 10 January 2020).

43. OECD. Biotechnology for Sustainable Growth and Development; OECD Publishing: Paris, France, 2004; Available online: http://www.oecd.org/science/emerging-tech/33784888.PDF (accessed on 26 August 2020).

44. European Commission (EC). Updated Bioeconomy Strategy: A sustainable Bioeconomy for Europe: Strengthening the Connection between Economy, Society and the Environment; European Commission: Brussels, Belgium, 2018; Available online: https://ec.europa.eu/research/bioeconomy/pdf/ec_bioeconomy_strategy_2018.pdf\#view= fit\&pagemode=none (accessed on 26 August 2020).

45. Levidow, L.; Birch, K.; Papaioannou, T. EU agri-innovation policy: Two contending visions of the bio-economy. Crit. Policy Stud. 2012, 6, 40-65. [CrossRef]

46. Korhonen, J.; Koskivaara, A.; Toppinen, A. Riding a Trojan horse? Future pathways of the fiber-based packaging industry in the bioeconomy. For. Policy Econ. 2018, 110, 101799. [CrossRef]

47. Kleinschmit, D.; Lindstad, B.H.; Thorsen, B.J.; Toppinen, A.; Roos, A.; Baardsen, S. Shades of green: A social scientific view on bioeconomy in the forest sector. Scand. J. For. Res. 2014, 29, 402-410. [CrossRef]

48. Hodge, D.; Brukas, V.; Giurca, A. Forests in a bioeconomy: Bridge, boundary or divide? Scand. J. For. Res. 2017, 32, 582-587. [CrossRef]

49. Bueso, Y.F.; Tangney, M. Synthetic biology in the driving seat of the bioeconomy. Trends Biotechnol. 2017, 35, 373-378. [CrossRef] [PubMed]

50. Mace, G.M. The ecology of natural capital accounting. Oxf. Rev. Econ. Policy 2019, 35, 54-67. [CrossRef]

51. Obst, C. Reflections on natural capital accounting at the national level: Advances in the system of environmental-economic accounting. Sustain. Account. Manag. Policy J. 2015, 6, 315-339. [CrossRef]

52. Bateman, I.J.; Mace, G.M. The natural capital framework for sustainably efficient and equitable decision making. Nat. Sustain. 2020. [CrossRef]

53. Potschin, M.B.; Haines-Young, R.H. Ecosystem services: Exploring a geographical perspective. Prog. Phys. Geogr. 2011, 35, 575-594. [CrossRef]

54. Natural Capital Coalition. Natural Capital Protocol. Available online: https://naturalcapitalcoalition.org/ natural-capital-protocol/ (accessed on 26 August 2020). 
55. TEEB. The Economics of Ecosystems and Biodiversity: Mainstreaming the Economics of Nature: A Synthesis of the Approach, Conclusions and Recommendations of TEEB. Available online: http://www.teebweb.org/ our-publications/teeb-study-reports/synthesis-report/ (accessed on 8 April 2020).

56. SEEA. Global Assessment of Environmental-Economic Accounting and Supporting Statistics. Available online: https:/unstats.un.org/unsd/statcom/49th-session/documents/BG-Item3h-2017-GlobalAssessment-of-Environmental-Economic-Accounting-E.pdf (accessed on 8 April 2020).

57. TEEB. Measuring What Matters in Agriculture and Food Systems: A Synthesis of the Results and Recommendations of TEEB for Agriculture and Food's Scientific and Economic Foundations Report; UN Environment: Geneva, Switzerland, 2018.

58. Ramcilovic-Suominen, S.; Pülzl, H. Sustainable development-A 'selling point' of the emerging EU bioeconomy policy framework? J. Clean. Prod. 2018, 172, 4170-4180. [CrossRef]

59. Piotrowski, S.; Carus, M.; Essel, R. Global Bioeconomy in the Conflict Between Biomass Supply and Demand. Ind. Biotechnol. 2015, 11, 308-315. [CrossRef]

60. Dietz, T.; Börner, J.; Förster, J.; von Braun, J. Governance of the bioeconomy: A global comparative study of national bioeconomy strategies. Sustainability 2018, 10, 3190. [CrossRef]

61. Pelenc, J.; Ballet, J. Strong sustainability, critical natural capital and the capability approach. Ecol. Econ. 2015, 112, 36-44. [CrossRef]

62. Maseyk, F.J.F.; Mackay, A.D.; Possingham, H.P.; Dominati, E.J.; Buckley, Y.M. Managing natural capital stocks for the provision of ecosystem services. Conserv. Lett. 2017, 10, 211-220. [CrossRef]

63. Pan, Y.; Vira, B. Exploring natural capital using bibliometrics and social media data. Ecol. Soc. $2019,24$. [CrossRef]

64. Jones, L.; Norton, L.; Austin, Z.; Browne, A.L.; Donovan, D.; Emmett, B.A.; Grabowski, Z.J.; Howard, D.C.; Jones, J.P.G.; Kenter, J.O. Stocks and flows of natural and human-derived capital in ecosystem services. Land Use Policy 2016, 52, 151-162. [CrossRef]

65. Hein, L.; Bagstad, K.; Edens, B.; Obst, C.; de Jong, R.; Lesschen, J.P. Defining ecosystem assets for natural capital accounting. PLoS ONE 2016, 11, e0164460. [CrossRef]

66. Ekins, P.; Simon, S.; Deutsch, L.; Folke, C.; De Groot, R. A framework for the practical application of the concepts of critical natural capital and strong sustainability. Ecol. Econ. 2003, 44, 165-185. [CrossRef]

67. Cohen, F.; Hepburn, C.J.; Teytelboym, A. Is Natural Capital Really Substitutable? Annu. Rev. Environ. Resour. 2019, 44, 425-448. [CrossRef]

68. Helm, D. Natural capital: Assets, systems, and policies. Oxf. Rev. Econ. Policy 2019, 35, 1-13. [CrossRef]

69. D'Amato, D.; Droste, N.; Allen, B.; Kettunen, M.; Lähtinen, K.; Korhonen, J.; Leskinen, P.; Matthies, B.D.; Toppinen, A. Green, circular, bio economy: A comparative analysis of sustainability avenues. J. Clean. Prod. 2017, 168, 716-734. [CrossRef]

70. D'Amato, D.; Gaio, M.; Semenzin, E. A review of LCA assessments of forest-based bioeconomy products and processes under an ecosystem services perspective. Sci. Total Environ. 2020. [CrossRef]

71. Philp, J. The bioeconomy, the challenge of the century for policy makers. New Biotechnol. 2018, 40, 11-19. [CrossRef]

72. Schütte, G. What kind of innovation policy does the bioeconomy need? New Biotechnol. 2018, 40, 82-86. [CrossRef] [PubMed]

73. Wesseler, J.; von Braun, J. Measuring the bioeconomy: Economics and policies. Annu. Rev. Resour. Econ. 2017, 9, 275-298. [CrossRef]

74. Sanz-Hernández, A.; Esteban, E.; Garrido, P. Transition to a bioeconomy: Perspectives from social sciences. J. Clean. Prod. 2019, 224, 107-119. [CrossRef]

75. Abson, D.J.; von Wehrden, H.; Baumgärtner, S.; Fischer, J.; Hanspach, J.; Härdtle, W.; Heinrichs, H.; Klein, A.M.; Lang, D.J.; Martens, P.; et al. Ecosystem services as a boundary object for sustainability. Ecol. Econ. 2014, 103, 29-37. [CrossRef]

76. Schröter, M.; Koellner, T.; Alkemade, R.; Arnhold, S.; Bagstad, K.J.; Erb, K.-H.; Frank, K.; Kastner, T.; Kissinger, M.; Liu, J. Interregional flows of ecosystem services: Concepts, typology and four cases. Ecosyst. Serv. 2018, 31, 231-241. [CrossRef]

77. Global Bioeconomy Summit (GBS). Global Bioeconomy Summit Communique: Innovation in the Global Bioeconomy for Sustainable and Inclusive Transformation and Wellbeing. 2018. Available online: https: //gbs2018.com/fileadmin/gbs2018/Downloads/GBS_2018_Communique.pdf (accessed on 26 August 2020). 
78. Standing Committee on Agricultural Research (SCAR). Bioeconomy Strategic Working Group. Available online: https://www.scar-swg-sbgb.eu/ (accessed on 20 July 2020).

79. Ronzon, T.; Piotrowski, S.; M'Barek, R.; Carus, M. A systematic approach to understanding and quantifying the EU's bioeconomy. Bio-Based Appl. Econ. J. 2017, 6, 1-17. [CrossRef]

80. O'Brien, M.; Wechsler, D.; Bringezu, S.; Schaldach, R. Toward a systemic monitoring of the European bioeconomy: Gaps, needs and the integration of sustainability indicators and targets for global land use. Land Use Policy 2017, 66, 162-171. [CrossRef]

81. Cristóbal, J.; Matos, C.T.; Aurambout, J.-P.; Manfredi, S.; Kavalov, B. Environmental sustainability assessment of bioeconomy value chains. Biomass Bioenergy 2016, 89, 159-171. [CrossRef]

82. Karvonen, J.; Halder, P.; Kangas, J.; Leskinen, P. Indicators and tools for assessing sustainability impacts of the forest bioeconomy. For. Ecosyst. 2017, 4, 2. [CrossRef]

83. Crenna, E.; Sozzo, S.; Sala, S. Natural biotic resources in LCA: Towards an impact assessment model for sustainable supply chain management. J. Clean. Prod. 2018, 172, 3669-3684. [CrossRef]

84. Norton, L.R.; Smart, S.M.; Maskell, L.C.; Henrys, P.A.; Wood, C.M.; Keith, A.M.; Emmett, B.A.; Cosby, B.J.; Thomas, A.; Scholefield, P.A.; et al. Identifying effective approaches for monitoring national natural capital for policy use. Ecosyst. Serv. 2018, 30, 98-106. [CrossRef]

85. DeFries, R.; Nagendra, H. Ecosystem management as a wicked problem. Science 2017, 356, $265-270$. [CrossRef] [PubMed]

86. Natural Capital Project. Available online: https://naturalcapitalproject.stanford.edu/ (accessed on 25 August 2020).

87. Pascual, U.; Palomo, I.; Adams, W.M.; Chan, K.M.A.; Daw, T.M.; Garmendia, E.; Gómez-Baggethun, E.; de Groot, R.S.; Mace, G.M.; Martín-López, B.; et al. Off-stage ecosystem service burdens: A blind spot for global sustainability. Environ. Res. Lett. 2017, 12, 75001. [CrossRef]

88. Ouyang, Z.; Song, C.; Zheng, H.; Polasky, S.; Xiao, Y.; Bateman, I.J.; Liu, J.; Ruckelshaus, M.; Shi, F.; Xiao, Y.; et al. Using gross ecosystem product (GEP) to value nature in decision making. Proc. Natl. Acad. Sci. USA 2020. [CrossRef]

89. Kelleher, L.; Henchion, M.; O'Neill, E. Policy Coherence and the Transition to a Bioeconomy: The Case of Ireland. Sustainability 2019, 11, 7247. [CrossRef]

90. United Nations General Assembly. Transforming our World: The 2030 Agenda for Sustainable Development; United Nations Publ.: Tokio, Japan, 2015. [CrossRef]

91. European Commission (EC). The European Green Deal: Striving to Be the First Climate Neutral Continent; European Commission: Brussels, Belgium, 2019; Available online: https://eur-lex.europa.eu/legal-content/ EN/TXT/?qid=1596443911913\&uri=CELEX:52019DC0640\#document2 (accessed on 26 August 2020).

92. European Commission (EC). The European Biodiversity Strategy 2030: Bringing Nature Back into Our Lives; European Commission: Brussels, Belgium, 2020; Available online: https://eur-lex.europa.eu/legal-content/ EN/TXT/?qid=1590574123338\&uri=CELEX:52020DC0380 (accessed on 26 August 2020).

93. Vardon, M.; Castaneda, J.-P.; Nagy, M.; Schenau, S. How the System of Environmental-Economic Accounting can improve environmental information systems and data quality for decision making. Environ. Sci. Policy 2018, 89, 83-92. [CrossRef]

94. Bateman, I.J.; Harwood, A.R.; Mace, G.M.; Watson, R.T.; Abson, D.J.; Andrews, B.; Binner, A.; Crowe, A.; Day, B.H.; Dugdale, S.; et al. Bringing Ecosystem Services into Economic Decision-Making: Land Use in the United Kingdom. Science 2013, 341, 45-50. [CrossRef]

95. Kareiva, P.; Tallis, H.; Ricketts, T.H.; Daily, G.C.; Poalsky, S. Natural Capital: Theory and Practice of Mapping Ecosystem Services; Oxford University Press: Oxford, UK, 2011; ISBN 0199589003.

96. Vandermeulen, V.; Van der Steen, M.; Stevens, C.V.; Van Huylenbroeck, G. Industry expectations regarding the transition toward a biobased economy. Biofuels Bioprod. Biorefining 2012, 6, 453-464. [CrossRef]

97. Dupont-Inglis, J.; Borg, A. Destination bioeconomy-The path towards a smarter, more sustainable future. New Biotechnol. 2018, 40, 140-143. [CrossRef]

98. European Investment Bank (EIB). Natural Capital Financing Facility (NCFF). Available online: https: //www.eib.org/en/products/blending/ncff/index.htm (accessed on 21 July 2020).

99. Lange, G.-M.; Wodon, Q.; Carey, K. The Changing Wealth of Nations 2018: Building a Sustainable Future; The World Bank: Washington, DC, USA, 2018. 
100. Bell, J.; Paula, L.; Dodd, T.; Németh, S.; Nanou, C.; Mega, V.; Campos, P. EU ambition to build the world's leading bioeconomy-Uncertain times demand innovative and sustainable solutions. New Biotechnol. 2018, 40, 35-40. [CrossRef]

101. Seghetta, M.; Hou, X.; Bastianoni, S.; Bjerre, A.-B.; Thomsen, M. Life cycle assessment of macroalgal biorefinery for the production of ethanol, proteins and fertilizers-A step towards a regenerative bioeconomy. J. Clean. Prod. 2016, 137, 1158-1169. [CrossRef]

102. Aguilar, A.; Twardowski, T.; Wohlgemuth, R. Bioeconomy for Sustainable Development. Biotechnol. J. 2019, 14, 1800638. [CrossRef] [PubMed]

103. European Union (EU). The 7th Environment Action Programme (7th EAP); European Union: Bruseels, Belgium, 2014; Available online: https://eur-lex.europa.eu/legal-content/EN/TXT/?uri=CELEX:32013D1386 (accessed on 26 August 2020).

104. European Environment Agency. The European Environment-State and Outlook Report Synthesis; European Environment Agency: Copenhagen, Denmark, 2015.

105. Klein, A.-M.; Vaissiere, B.E.; Cane, J.H.; Steffan-Dewenter, I.; Cunningham, S.A.; Kremen, C.; Tscharntke, T. Importance of pollinators in changing landscapes for world crops. Proc. R. Soc. B Biol. Sci. 2007, 274, 303-313. [CrossRef] [PubMed]

106. Gallai, N.; Salles, J.-M.; Settele, J.; Vaissière, B.E. Economic valuation of the vulnerability of world agriculture confronted with pollinator decline. Ecol. Econ. 2009, 68, 810-821. [CrossRef]

107. IPBES. Assessment Report on Pollinators, Pollination and Food Production; Potts, S.G., Imperatriz-Fonseca, V.L., Ngo, H.T., Eds.; Secretariat of the Intergovernmental Science-Policy Platform on Biodiversity and Ecosystem Services: Bonn, Germany, 2016.

108. European Environment Agency (EEA). Natural Capital Accounting in Support of Policymaking in Europe. Available online: https://www.eea.europa.eu/publications/natural-capital-accounting-in-support (accessed on 26 August 2020).

109. Meyer, R. Bioeconomy strategies: Contexts, visions, guiding implementation principles and resulting debates. Sustainability 2017, 9, 1031. [CrossRef]

110. Ouyang, Z.; Zheng, H.; Xiao, Y.; Polasky, S.; Liu, J.; Xu, W.; Wang, Q.; Zhang, L.; Xiao, Y.; Rao, E.; et al. Improvements in ecosystem services from investments in natural capital. Science 2016, 352, 1455-1459. [CrossRef] [PubMed]

111. Ruijs, A.; Vardon, M.; Bass, S.; Ahlroth, S. Natural capital accounting for better policy. Ambio 2019, 48, 714-725. [CrossRef]

112. Jordan, A.; Lenschow, A. Environmental policy integration: A state of the art review. Environ. Policy Gov. 2010, 20, 147-158. [CrossRef]

(C) 2020 by the authors. Licensee MDPI, Basel, Switzerland. This article is an open access article distributed under the terms and conditions of the Creative Commons Attribution (CC BY) license (http://creativecommons.org/licenses/by/4.0/). 